\title{
Reduced Vision and Refractive Errors, Results from a School Vision Screening Program in Kanchanpur district of Far Western Nepal
}

\author{
Awasthi $\mathrm{S}^{1}$, Pant BP2 , Dhakal HP³
}

${ }^{1,2}$ Geta Eye Hospital, Nepal

\section{ABSTRACT}

${ }^{3}$ Department of Pathology, The Norwegian Radium Hospital, Oslo, Norway

\section{Corresponding Author}

Suresh Awasthi, B.Optom (TU), MPhil student ( $\mathrm{HiBu})$

Department of Optometry and visual sciences, Buskerud University College

Frogsvei 41, 3611 Kongsberg, Norway

Email.suresh.buc@gmail.com

\section{Background}

At present there is no data available on reduced vision and refractive errors in school children of far western Nepal. So, school screening records were used to obtain data useful for planning of refractive services.

\section{Methods}

Data are provided from school screening conducted by Geta Eye Hospital during February/March 2008. The cases with complete data sets on visual acuity, refractive error and age were included and analyzed using computer software.

\section{Results}

Of 1165 children (mean age $11.6 \pm 2.5$ years) examined, $98.8 \%(n=1151)$ had uncorrected visual acuity of $6 / 9$ and better in at least one eye whereas $1.2 \%(n=14)$ had acuity $6 / 12$ and worse in both eyes. Among them, either eye of 9 children improved to $6 / 9$ and better with correction. However, visual acuity was $6 / 12$ and worse in both eyes of 5 children even after correction. There were 24 children with refractive errors (myopia, $1.54 \% ; n=18$ and hypermetropia, $0.51 \% ; n=6$ ) in at least one eye. The spherical equivalent refraction was not significantly different with age and gender.

\section{Conclusions}

The incidence of reduced vision and refractive errors among school children of this semi rural district were low.

\section{Key Words}

reduced vision, refractive error, school children, school screening 


\section{INTRODUCTION}

SchoolvisionscreeningisconductedinNepal by Nepal NetraJyotiSanghthroughvariousEyeHospitalstoidentify childrenwithvisionproblemsandofferthemthecorrective measures..$^{910}$ Aftereyeexamination thesechildrenwere providedcorrectiveglassesatnocost.Generallychildren are not awareabout theirvision problems, especially if theproblemexistssinceearlychildhood orthevision is reducedinoneeyeonly.Evenwhentheyareaware, they mightnotreport.Thiswayvisionproblemamongchildren cangoundetected.Thusscreening programsarehelpful in identifying children with reduced vision. Reduced visionduetorefractiveerrorisaseriousproblemamong schoolagechildrenandifnotcorrectedintimecanlimit theirclassroomperformanceandeconomicprospectin laterlife. ${ }^{12}$ Thelargestproportion ofreducedvisiondueto refractiveerrorsworldwidehasbeenreportedfromurban areasinsouth-eastAsiaandChina. ${ }^{12}$ However,allcountries insouthAsiaandChinadonotsharesimilarprevalenceof reducedvisionandrefractiveerrors. ${ }^{3,5,11,12,12,18}$ Inaseries ofstudiescalled Refractiveerrorstudyinchildren(RESC) largeproportion ofchildrenwithreducedvision(6/18or worse) wereduetorefractiveerrorswerereportedfrom China $(94.9 \%)^{5}$ followed by India $(61 \%)^{3}$ and Nepal $(56 \%) .^{11}$

Studiesreported myopiaprevalenceof 1.2\%inNepal, ${ }^{11}$ 4.1\%in India ${ }^{3}$ and $14.9 \%$ inChina. ${ }^{18}$ WithinNepal,studies amongschoolchildrenfromKathmandureportedhigher prevalence of refractive errors, $8.1 \%$ (myopia $=4.3 \%$; astigmatism $=2.5 \%$ and hypermetropia $=1.3 \%),{ }^{8} 18.6 \%{ }^{14}$ and $21.8 \%{ }^{16}$ comparedtothosefromoutsideKathmandu.

${ }^{4,11}$ Weassumedlowprevalenceofrefractiveerrorsamong schoolchildreninKanchanpur.Thelowprevalencewas assumed in view of the rural location of Kanchanpur district.

The aim of this study was to elucidate the incidence of reducedvisionandrefractiveerrorsamongschoolchildren fromKanchanpurdistrictofFarWesternNepalaccording to their types and relationship with age and gender.

\section{METHODS}

This is a retrospective descriptive study on reduced visionandrefractiveerrorsamongschoolchildrenfrom KanchanpurdistrictofFarwesternNepal.Thedatawere collected by a mobile team of Geta Eye Hospital within schoolpremisesduringitsregularschoolvisionscreening.

Of4000schoolchildrenscreenedduringFebruary/march 2008,only 1165 hadcompletesetofdataonvisualacuity, refraction,ageandgenderwerethusincludedinthisstudy. Other records that lacked information on visual acuity, refraction and age were not included in the study. The children enrolled in grade 1 to 10 from 3 schools were included in the study.

Thepublicschoolsaccessiblebyroadswereselectedfor thescreening.Thescreening programwasconductedin collaborationwitheducationandpublichealthofficesinthe district.Screeningteamconsisted ofanoptometristandan assistant.Thetestsincludedmeasurementofvisualacuity, anteriorsegmentevaluation, noncycloplegicrefraction anddirectophthalmoscopy.Anassistantassessedvisual acuity with a Snellens' vision chart at 6 meter distance using daylightfrom 10 amto $4 \mathrm{pm}$. Acuitywastestedfor eacheyeseparately.Anoptometristperformedallother tests.Anteriorsegmentwasassessedbyafocusabletorch. Retinoscopy was performed among all children at 50 centimeterswithchildren'seyesfixatedonvisionchartat 6 meters.Aretinoscopicreflexwasquicklyswipedacross pupillaryareawithastreakretinosocpe(Heine,Germany). Subjectiverefraction withtrialframewasperformedonly ifretinoscopysuggestedrefractiveerrors, and/orvisual acuitywaslessthan6/6.Ophthalmoscopywasperformed incasessuspected ofposteriorsegmentabnormalities. Glasseswereprescribedand provided byanoptometrist to those who needed.Children with prescription of 0.5 Dioptersphericalequivalentrefractionandmoreineither eyewereprescribedglasses. Antibioticeyedropsand/or ointmentswereprovidedwheninfectionswereobserved, like conjunctivitis. Children with all other pathological conditionswerereferred toGetaEyeHospitalforfurther evaluation.Registration ofallchildrenwasdonewiththe helpofclassteachersandstudentvolunteers.Institutional permission was obtained for the use of the data for the study.

The data were analyzed using SPSS (17.0) computer software.Datawerepresentedintheformoftables.The eyes with uncorrected visual acuity 6/12 and worse werecategorizedashavingreducedvision.Myopiaand hypermetropiawerediagnosedforeyeswith prescription of $0.5 \mathrm{D}$ spherical equivalent and more. The Spherical equivalentrefraction(SER)wascalculatedbydividingthe cylindricalprescriptionby 2 andaddingittothespherical prescription. Any eye with \pm 0.75 cylinder Diopter and more was considered to have astigmatism. A child was myopic if one or both eyes had myopia; hyperopic, if oneorbotheyeshad hyperopia, provided therewasno myopiaintheothereyeandemmetropicifbotheyeshad emmetropia.Similarly, achild withastigmatisminoneor both eyes was considered to have astigmatism.

\section{RESULTS}

Among 1165 records analyzed, there were $43.9 \%$ boys 
and $56.1 \%$ girls.Theparticipantincludedrangedfrom 5 to19yearsofagewithlowestnumberofparticipantswere in 5 and $19(n=1)$ year age group and highest number in $12(n=170)$ year age group. The largest proportion of children, $13.2 \%(n=154)$ were in grade 7 and smallest proportion $0.77 \%(n=9)$ in grade 10 . In other grades fairlyevendistributionofchildrenrangingfrom63to154 werefound.Thelargestcaste/ethnicgroupwasChhetri (27.1\%), followed by Dalit (25\%), Brahmin (23.2\%) and Tharu (12.5\%).

\section{VISUAL ACUITY}

Altogether2330eyesof1165children (meanage11.6 \pm 2.5 years)wereevaluated.Uncorrectedvisualacuitywas $6 / 9$ and betterinatleastoneeyeof $98.8 \%(n=1151)$ children (table 1). The uncorrected visual acuity in right eyes ranged from $6 / 6$ to $3 / 60$ and in left eyes it ranged from $6 / 6$ to $5 / 60$. With correction, $99.57 \%(n=1160)$ children obtainedvisualacuityof6/9andbetterinatleastoneeye andnoneofthechildrenhadworsethan6/60inbotheyes. Uncorrected visualacuity6/12andworsewerepresent in both eyes of $1.2 \%(n=14)$ and one eye of 8 children. Altogether22childrenaged10to16yearshaduncorrected visual acuity $6 / 12$ and worse (reduced vision) in at least one eye. Among them, visual acuity improved to $6 / 9$

or better in at least one eye of $64.28 \%(n=9)$ children. However, visual acuity did not improve to $6 / 9$ or better in both eyes of $0.42 \%(n=5)$ children. A significant correlationbetweenuncorrectedvisualacuityinrightand left eyes $(r=0.68 ; p<0.0001)$ was observed.

Table 1. Distribution of uncorrected and corrected visual acuity

\begin{tabular}{|cccc} 
& Visual acuity & $\begin{array}{c}\text { Uncorrected visual } \\
\text { acuity, No. (\%) }\end{array}$ & $\begin{array}{c}\text { Corrected visual } \\
\text { acuity, No. (\%) }\end{array}$ \\
\hline Both eyes & $\geq 6 / 9$ & $1143(98.1)$ & $1153(98.96)$ \\
One eye & $\geq 6 / 9$ & $8(0.68)$ & $7(0.6)$ \\
Better eye & $\geq 6 / 12$ to $\leq 6 / 18$ & $6(0.51)$ & $4(0.34)$ \\
& $\geq 6 / 24$ to $\leq 6 / 60$ & $7(0.6)$ & $1(0.08)$ \\
\hline Total & $<6 / 60$ & $1(0.08)$ & $0(0.00)$ \\
& & $1165(100)$ & $1165(100)$
\end{tabular}

\section{REFRACTIVE ERRORS}

Refractiveerrorswerepresentinatleastoneeyeof $2.06 \%$ $(n=24)$ and botheyes of $1.45 \%(n=17)$ children. Myopia was present in $1.54 \%(n=18)$ and hypermetropia in $0.51 \%(n=6)$ children (table2).Thesphericalequivalent refraction (SER) for both eyes was within -4.0 to +4.5 Diopters.Oftheeyeswithrefractiveerrors, $63.6 \%(n=28)$ were within $\pm 2.0 \mathrm{D}$. A significant correlation wasfound betweensphericalequivalentrefractioninrightandleft eyes $(r=0.90 ; p<0.0001)$. Astigmatism was present in either eye of $0.6 \%(n=7)$ children.

Table 2. Distribution of refractive errors

\begin{tabular}{|ccc|}
\hline Eye & Refractive status & Children No. (\%) \\
\hline Both eyes & Emmetropia & $1141(97.9)$ \\
\hline One eye & Myopia & $2(0.17)$ \\
\hline Both eyes & Myopia & $16(1.37)$ \\
\hline One eye & Hypermetropia & $5(0.43)$ \\
\hline Both eyes & Hypermetropia & $1(0.08)$ \\
\hline Total & & $1165(100)$ \\
\hline
\end{tabular}

\section{EFFECT OF AGE AND GENDER}

Refractiveerrorswerepresentamongchildrenbetween 7to16yearswith thelargestproportion, among 15 year olds. Six out of 89,15 year old children had refractive errors ( $m y o p i a=5$; hyperopia $=1$ ). Children from 7 to

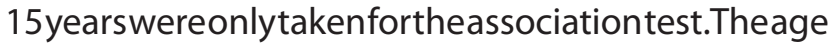
wasnotassociatedsignificantlywithsphericalequivalent refraction in right $\left(X^{2}, p=0.53\right)$ and lefteyes $\left(X^{2}, p=0.11\right)$. GenderwasalsonotassociatedsignificantlywithSERin right $\left(X^{2}, p=0.41\right)$ and left eyes $\left(X^{2}, p=0.44\right)$.

\section{DISCUSSION}

Visual acuity

Themajorityofschoolchildrenhadnormal/nearnormal uncorrectedvisualacuity.Theproportionofuncorrected reduced vision was slightly lower than that reported in eastern Nepal (2.9\%). ${ }^{11}$ IneasternNepal 138 out of 4803 children had visual acuity $6 / 12$ and worse in eithereye. Contrarytothesereports, largerproportions of children with uncorrected reduced vision were reported from Kathmandu. $8,14,16$ The incidence of corrected reduced vision in this study was similar to that reported from Kathmand $\mathrm{u}^{8,14,16}$ and eastern Nepal. ${ }^{11}$ In eastern Nepal 65 out of 4803 children had reduced vision even after correction.Thereducedvisionevenaftercorrectionmust be due to causes other than refractive errors.

\section{Refractive errors}

Refractive errors among school children in this south western district of Nepal were low and comparable to that reported fromeastern Nepal (2.6\%). ${ }^{11}$ In thisstudy, majority of the eyes with refractive errors were myopic whereasmajorityoftheeyeswerehyperopicinthestudy from eastern Nepal. ${ }^{11}$ The reason for not finding many children with hyperopia might be under detection of hyperopiainthisstudyasfull refraction wasperformed 
only in eyes with below normal acuity. Another reason mightbethatcycloplegicrefractionwasnotperformed. The prevalence of myopia has been reported to vary between publicand privateschoolchildren., ${ }^{4,114}$ Lower educationalpressureamongpublicschoolchildrenand rigorousschoolingamong privateschoolchildrenhave beendiscussedasthereasonfortheobserveddifferences inrefractiveerrorprevalencebetween privateand public schoolchildren. ${ }^{.}$Thefactthatonlypublicschoolchildren wereincludedinthisstudymightsuggestreasonforlower prevalenceofrefractiveerrorsobserved.Oftheeyeswith reduced vision, almost $2 / 3^{\text {rd }}(64.28 \%)$ improved with refractivecorrection which wassimilartothatreported in other studies in Nepal $(56 \%)^{11}$ and India $(61 \%)^{3}$. However, thecriterionusedfordefining reducedvision duetorefractiveerrorinthisstudywas differentthanthat used in studies from eastern Nepal and Kathmandu. In thisstudy, refractiveerrorwasthecauseofuncorrected reducedvisioninaneyeimproving byatleast 2 lineswith correction.InstudiesfromeasternNepalandKathmandu, eyes improving to $6 / 9$ and better with correction were consideredtohavereducedvisionduetorefractiveerror. Contrarytothesestudies,largerproportionsofeyeswith reducedvisionduetorefractiveerrorswerereportedfrom China(94.9\%). ${ }^{5}$ Thismightpossiblybeduetomajority of theNepaleseethnicgroupsclosertothelndianpopulation.

\section{Effect of age and gender}

Studentsof15yearofagehadhighestnumberofchildren withrefractiveerrorspossiblyduetoexcessivereading. Children at this age are normally in grade 9 or 10. This isthetimewhentheyhavetoworkhardertopassschool boardexams.Thus, excessivereadingduringthisperiod might have increased the incidence. However, the SER in right and left eyes were not associated significantly withageandgender.Agewasreportedtobesignificantly associated withrefractiveerrorinanotherstudyaswell. ${ }^{11}$ Yet Another study reported significantly more myopia amonggirlsthan boys $(\mathrm{P}<0.01){ }^{2}$ Ourstudydidnothave sufficient numbers to make such deductions.

\section{CONCLUSION}

The incidence of reduced vision (1.2\%) and refractive errors (2.06\%) among school children of this semi rural district were low. Myopia was the dominant type of refractive errors accounting for more than $2 / 3^{\text {rd }}$ of the refractiveerrors. Most of themyopia wasfoundamong olderagegroup.Asrefractivecorrectioncouldimprove visualacuityinmajorityofthechildren,effectivescreening of refractiveerrors could help reducethe proportion of reduced vision among school children.

\section{ACKNOWLEDGEMENT}

The authors would like to thank Geta Eye Hospital, Dhangadhi (Nepal), Mr. R.C. Bhatta, Geta Eye Hospital (Nepal)andProf.FrankSchaeffel,UniversityofTuebingen (Germany) for providing generous support at various levels during preparation of this manuscript.

\section{REFERENCES}

1. CentralBureauofStatistics.NepalCensus2001:Casteand ethnicity. Kathmandu:Central Bereau of statistics; [cited 2009, July 3]. Available from: http://www.cbs.gov.np/ national_report_2001.php

2. Congdon N, Wang Y, Song Y, Choi K, Zhang M, Zhou Z, etal.Visualdisability, visualfunction, and myopiaamong rural chinese secondary school children: the Xichang PediatricRefractiveErrorStudy(X-PRES)--report 1.Invest Ophthalmol Vis Sci 2008;49:2888-94.

3. Dandona R, Dandona L, Srinivas M, Sahare P, Narsaiah $S, M u n o z S$. R, et al. Refractive error in children in a rural populationinIndia.InvestOphthalmolVisSci2002;43:61522.

4. Garner LF, Owens H, Kinnear RF, Frith MJ. Prevalence of myopiainSherpaandTibetanchildreninNepal.OptomVis Sci 1999;76:282-5.

5. HeM,ZengJ,LiuY,XuJ,PokharelGP,Ellwein LB.Refractive errorandvisualimpairmentinurbanchildreninsouthern china. Invest Ophthalmol Vis Sci 2004;45:793-9.

6. Murthy GV, Gupta SK, Ellwein LB, Munoz SR, Pokharel $\mathrm{GP}$, Sanga L et al. Refractive error in children in an urban population in New Delhi. Invest Ophthalmol Vis Sci 2002;43:623-31.

7. Naidoo KS, Raghunandan A, Mashige KP, Govender $P$, Holden BA, Pokharel GP et al. Refractive error and visual impairment in African children in South Africa. Invest Ophthalmol Vis Sci 2003;44:3764-70.

8. Nepal BP, Koirala S, Adhikary S, Sharma AK. Ocular morbidityinschoolchildreninKathmandu.BrJOphthalmol 2003;87:531-4.

9. NepalNetrajyotiSangh,Annualreport2009,NNJSAnnual report 2009.

10. NepalNetrajyotiSangh.NationalEyeSightprogram.[cited 2010 Sep 10]. Available from: http://www.nnjs.org.np/ programs/national_eye_sight_programs.php

11. Pokharel GP, Negrel AD, MunozSR, Ellwein LB. Refractive Error Study in Children: results from Mechi Zone, Nepal. Am J Ophthalmol 2000;129:436-44. 
12. Resnikoff S, Donatella P, Mariotti SP, Pokharel GP.Global magnitude of visual impairment caused by uncorrected refractive error. Bulletin of World Health Organization. January [cited 2008 Sep 8]. Available from: http://www. who.int/bulletin/volumes/ 86/1/07-041210.pdf

13. Rose KA, Morgan IG, Smith W, Burlutsky G, Mitchell P, Saw SM. Myopia, lifestyle, and schooling in students of ChineseethnicityinSingaporeandSydney.ArchOphthalmol 2008; 126:527-30.

14. SapkotaYD,AdhikariBN,PokharelGP,PoudyalBK,Ellwein LB.Theprevalenceofvisualimpairmentinschoolchildren of upper-middle socioeconomic status in Kathmandu. Ophthalmic Epidemiol 2008 15:17-23.

15. Saw SM, Goh, PP, Cheng A, Shankar A, Tan DTH, Ellwein LB.Ethnicityspecificprevalencesofrefractiveerrorsvaryin AsianChildreninneighboringMalaysiaandSingapore.Br.J. Ophth 2006(90):1230-5.

16. Shrestha RK, Joshi MR, Ghising R, Pradhan P, Shakya S, Rizyal A. Ocular morbidity among children studying in privateschoolsofKathmanduvalley:A prospectivecross sectional study. Nepal Med Coll J 2006;8:43-6.

17. The Nepal Blindness Survey team. The Epidemiology of Blindness in Nepal: Report of the 1981 Blindness survey. Kathmandu.Seva Foundation.

18. Zhao J, Pan X, Sui R, Munoz S. R, Sperduto R. D, \& Ellwein L.B.RefractiveErrorStudyinChildren:resultsfromShunyi District, China. Am J Ophthalmol 2000;129:427-35. 